\title{
Estimasi dosis serap sel kanker nasofaring dan lidah dari perlakukan radioterapi konvensional cobalt-60 berbasis MCNPX
}

\author{
Wihantoro*, Aris Haryadi, Bilalodin dan Arif Hidayat \\ Program Studi Fisika, Fakultas MIPA, Universitas Jenderal Soedirman \\ Jl Dr. Suparno 61 Grendeng, Purwokerto (53123) \\ *email:wihantoro@unsoed.ac.id
}

\begin{abstract}
Abstrak- Modifikasi radioterapi diperlukan untuk memaksimalkan dosis serap sel kanker dan meminimalkan dosis terimaan organ sekitarnya. Pada perlakuan kanker nasofaring, target penyinaran PTV dilakukan dengan menggeser posisi obyek $3 \mathrm{~cm}$ ke depan dan $2 \mathrm{~cm}$ ke atas dari pusat GTV. Penelitian ini menitikberaktan pada penentuan dosis serap radiasi kanker nasofaring dan lidah, dengan teknik penyinaran latero-lateral (sudut $90^{\circ}$ dan $270^{\circ}$ ) dan supraclave (sudut $0^{\circ}$ ). Berbasis pemrograman MCNPX, berkas sinar gamma dimodelkan berdasar spesifikasi head unit GammaBeam100-80, SSD $80 \mathrm{~cm}$, medan radiasi untuk supraclave $(12 \mathrm{x} 12) \mathrm{cm} 2 \mathrm{dan}(17 \mathrm{x}$ 9) $\mathrm{cm} 2$ untuk latero-lateral. Hasil menarik yang masih perlu dikaji lanjut adalah, dari total 2,0 Gy per fraksi penyinaran yang ditembakkan, dosis serap gabungan untuk penyinaran latero-lateral dan supraclave dari GTV dan PTV, masing-masing adalah 2,99 Gy dan 2,89 Gy. Sedang dosis terimaan pada lidah dari GTV dan PTV masing-masing adalah 0,16 Gy dan 0,13 Gy yang tergolong aman di bawah batas ambang dosis yang diperbolehkan.
\end{abstract}

Kata Kunci: Kanker Nasofaring, lidah, latero-lateral, supraclave, GTV dan PTV, dosis serap, MCNPX

\begin{abstract}
Modification of radiotherapy were presented to maximize the absorption dose of cancer cells and minimize the received of surrounding organs. As for nasopharyngeal cancer's treatment, the center of the radiation beam were shifted onto a position of $3 \mathrm{~cm}$ forward and $2 \mathrm{~cm}$ upwards from its GTV's center. This study focuses on the determination of radiation absorption dose for nasopharyngeal and tongue cancers, using radiation techniques of latero-lateral (beam direction of $90^{\circ}$ and 270o) and supraclave (0o of beam direction). Using the MCNPX code-programmed, the gamma ray beams were modeled based on the specifications of the head unit of GammaBeam100-80, SSD $80 \mathrm{~cm}$, the radiation field for the supraclave (12x 12) cm2 and (17 x 9) $\mathrm{cm} 2$ for latero-lateral. As from a total of $2.0 \mathrm{~Gy}$ per fraction of gamma beam irradiation, the absorption doses from both supraclave and lateral were 2.99 Gy and 2.89 Gy, each for GTV and PTV areas. Meanwhile, the dose received onto the tongue for the target GTV and PTV ware 0.16 Gy and 0.13 Gy, respectively, which was indeed, below the safety dose threshold allowed.
\end{abstract}

Key words: nasopharyngeal cancer, tongue, latero-lateral, supraclave, GTV dan PTV, absorbed dose, MCNPX

\section{PENDAHULUAN}

Sel kanker nasofaring atau kanker nasofaring terletak pada tenggorokan paling atas di belakang rongga hidung, di depan tulang belakang, di atas rongga mulut dan di bawah otak dan mata [1,2]. Perlakuan kanker nasofaring dengan radioterapi dilakukan untuk memaksimalkan dosis serap pada sel kankernya dan mencegah terjadinya penumpukan dosis pada satu atau beberapa organ sekitar. Teknik penyinaran dua medan radiasi, latero-lateral dan supraclave diterapkan untuk maksud ini[3]. Medan penyinaran lateral meliputi daerah tumor primer, sedangkan medan penyinaran supraclave meliputi daerah yang mengalami penyebaran pada kelenjar getah bening [4].
Penetapan dosis radiasi total untuk pasien diberikan dengan sistem fraksinasi, yaitu pemberian dosis total dibagi menjadi beberapa dosis radiasi penyinaran dalam jangka waktu tertentu. Menurut Komite Penanggulangan Kanker Nasional [3] pemberian dosis radiasi dilakukan selama 5 kali dalam seminggu, dengan dosis per fraksi/hari sebesar 4 Gy yang terdiri dari 2 Gy untuk tenik latero-lateral dan 2 Gy untuk supraclave. Juga dosis total yang diarahkan ke sel kanker nasofaring sebesar 60 70 Gy untuk penyinaran latero-lateral dan 50 Gy untuksupraclave[4,5].

Distribusi dosis radiasi Co-60 pada sel kanker dan organ sekitarnya didalam tubuh pasien tidak dapat diukur secara langsung menggunakan dosimeter. Oleh sebab itu diperlukan suatu simulasi yang dapat 
menentukan distribusi dosis radiasi yang diserap oleh tubuh. Salah satu metode yang digunakan adalah metode Monte Carlo dengan program MCNPX. Tujuan kajian ini adalah memodelkan phantom organ kepala, leher dan dada laki-laki dewasa serta menentukan distribusi dosis serap sinar gamma dari sumber Cobalt-60 pada kanker nasofaring dan organ sekitar yang fokus pada organ lidah dan kelenjar getah bening. Target penyinaran radiasi dibedakan dalam kontur GTV (gross tumour volume) pada pusat sel kanker nasofaring dan PTV (planning tumour volume) pada area organ-organ sekitar kanker. Organ lidah dijadikan fokus pada kajian ini, karena adanya gejala pasien yang mengalami ganggung tidak bisa meludah setelah mengalami perlakukan penyinaran kanker nasofaring $[4,5,6]$.

\section{LANDASAN TEORI}

\section{Fluks Foton dan Fluks Energi}

Fluks foton $(\phi)$ adalah jumlah foton $(\mathrm{dN})$ per satuan luas tertentu (dA).

$$
\phi=\frac{d N}{d A}
$$

Satuan fluks foton adalah foton $/ \mathrm{m}^{2}$.

Fluks energi $(\psi)$ didefinisikan sebagai jumlah energi $(\mathrm{dE})$ yang melintasi area $(\mathrm{dA})$.

$$
\psi=\frac{d E}{d A}
$$

Fluks energi memiliki satuan $\mathrm{MeV} / \mathrm{m}^{2}$ [7].

\section{Definisi Volume Kanker}

Definisi volume kanker merupakan prasyarat dalam perencanaan perawatan 3-D dan untuk memperoleh dosis yang akurat. Beberapa sasaran dan volume struktur kritis yang dapat membantu dalam proses perencanaan pengobatan dan memberikan dasar untuk perbandingan hasil pengobatan [5].
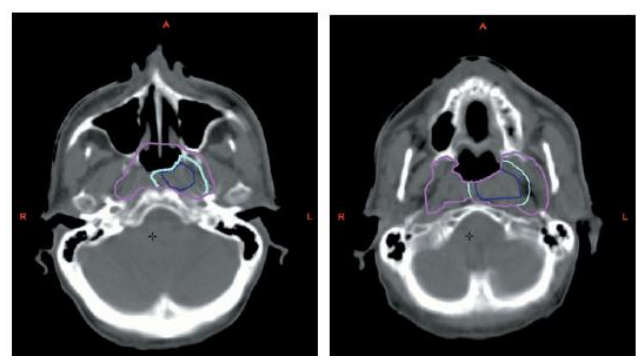

Gambar 1. garis Biru (GTV), Cyan (CTV), Ungu (PTV) dan di luar garis adalah organ beresiko $[5,6]$.

\section{METODE}

Arah penyinaran supraclave (sudut $0^{\circ}$ ) merujuk pada sumbu-y positif koordinat kartesian dan latera-lateral (sudut $90^{\circ}$ serta $270^{\circ}$ ).merujuk pada sumbu- $x$ positif dan negatif, dengan posisi obyek yang disinari horisontal (tidur) [5].

Geometri organ memanfaatkan input dalam program MCNPX Visual Editor meliputi densitas, material penyusun, bentuk dan ukuran surface $[8,9]$. Pemodelan organ kepala dan leher laki laki dewasa dibentuk mirip dengan aslinya dan bentuk geometri sesuai referensi yang dikeluarkan phantom Taiwan dengan spesifikasi laki-laki dewasa berumur 20 - 66 tahun, berat badan $69 \mathrm{~kg}$ dan tinggi badan $168,7 \mathrm{~cm}$ serta panjang kepala dan leher $27 \mathrm{~cm}$. Organ-organ yang terdapat di dalam geometri kepala dan leher yaitu nasofaring, mata, lidah dan kelenjar tiroid [10].

Selain setting input geometri, diperlukan juga setting input transport foton diantaranya jumlah foton yang dipancarkan sebanyak $2 \mathrm{x}$ $10^{8}$ foton serta tally $f 5$ dan $f 6$ untuk menghitung fluks energi per satuan luas dan dosis serap masing-masing organ dalam phantom [9].

\section{HASIL DAN PEMBAHASAN}

Teknik latero-lateral target penyinaran disimulasikan pada sel kanker daerah GTV (daerah pusat pertumbuhan) dan PTV (daerah bawah sel kanker). Sedangkan teknik supraclave target penyinaran disimulasikan pada daerah kelenjar getah bening di area sekitar dada. Target penyinaran dibuat berbeda guna mengetahui perbandingan distribusi dosis serap pada masing-masing target serta agar dapat merusak sel kanker dengan maksimum dan tidak terjadi penumpukan dosis radiasi pada bagian organ tertentu sehingga jaringan sehat yang terkena radiasi tidak mengalami kerusakan yang parah [11].

\section{Model Phantom Organ Kepala, Leher dan Dada Laki-laki Dewasa}

Bentuk geometri, densitas dan volume komposisi tiap organ dibuat berdasar model Phantom Taiwanese Reference Man (TRM) yang dibuat oleh Chang dkk. [10]. Pemodelan organ kepala, leher dan dada laki-laki dewasa secara tepat tidaklah mudah untuk dilakukan. Oleh karena itu dilakukan pendekatan dengan membuat geometri organ menggunakan bentuk silinder dan bola sehingga hampir menyerupai geometri organ sebenarnya (Gambar 2). Organ 
yang disimulasikan adalah kanker nasofaring, mata, lidah, dan kelenjar tiroid.

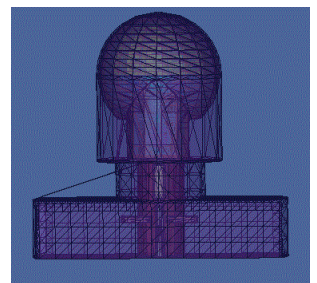

(a)

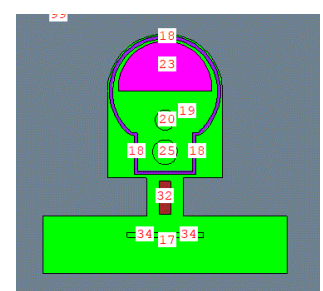

(b)
Gambar 2. Geometri phantom organ kepala, leher dan dada laki-laki dewasa hasil simulasi yang dipotong pada titik pusat kanker bidang- $x y$ (a)bentuk 3D dan (b) bentuk 2D

Geometri nasofaring dideskripsikan berupa bola berdiameter $1,55 \mathrm{~cm}$, densitas $1,03 \mathrm{~g} / \mathrm{cm}^{3}$, dan volume $1,95 \mathrm{~cm}^{3}$. Sementara geometro lidah bentuknya berupa silinder, berdiameter $3,88 \mathrm{~cm}$, panjang $2,89 \mathrm{~cm}$, densitas $1,03 \mathrm{~g} / \mathrm{cm}^{3}$, dan volume $69,54 \mathrm{~cm}^{3}$.

\section{Dosis Serap per organ}

Pada penyinaran lateral dilakukan dua target penyinaran yaitu target pusat sel kanker (GTV) dan bawah sel kanker (PTV). Sedangkan penyinaran supraclave target penyinaran pada daerah kelenjar getah bening. Penyinaran dengan target radiasi berbeda bertujuan agar sel kanker nasofaring memperoleh dosis serap maksimum dan homogen serta tidak merusak jaringan normal sekitar [9,12]. Dosis serap setiap organ dihasilkan dari masing-masing penyinaran dengan target pusat sel kanker dan penyinaran target bawah sel kanker dapat dilihat sebagai berikut:

Tabel 1. Dosis serap untuk target penyinaran GTV

\begin{tabular}{|c|c|c|c|c|}
\hline \multirow[b]{2}{*}{ Organ } & \multirow{2}{*}{$\begin{array}{c}\text { sp-clave } \\
0^{\circ} \\
(\max 2 \\
\text { Gy }) \\
\end{array}$} & \multicolumn{3}{|c|}{ latero-lateral } \\
\hline & & $\begin{array}{c}90^{\circ} \\
(\max 1 \\
\text { Gy) }\end{array}$ & $\begin{array}{c}270^{\circ} \\
(\max 1 \\
\text { Gy) }\end{array}$ & $\begin{array}{c}\text { Gab } \\
(\mathrm{max} \\
2 \mathrm{~Gy}) \\
\end{array}$ \\
\hline Kanker NF & 0,005 & 1,497 & 1,496 & 2,998 \\
\hline Mata kana & 0,004 & 0,657 & 0,656 & 1,317 \\
\hline Mata kiri & 0,004 & 0,597 & 0,596 & 1,197 \\
\hline Lidah & 0,002 & 0,080 & 0,080 & 0,162 \\
\hline Kel Tiroid & 0,116 & 0,026 & 0,026 & 0,168 \\
\hline
\end{tabular}

Target penyinaran supraclave (sudut $0^{\circ}$ ) berada pada bagian bawah leher daerah supraklavikula yang terdapat kelenjar getah bening. Daerah ini disinar karena potensi penyebaran sel kanker yang besar atau sudah ada sel kanker yang tersebar pada kelenjar getah bening penyebab sel kanker [13]. Target penyinaran sudut $0^{\circ}$ tidak diarahkan tepat pada sel kanker, karena organ sekitar bagian atas nasofaring terdapat banyak organ vital yang sensitif terhadap radiasi dan dapat menimbulkan efek samping dan komplikasi. Sehingga dosis serap sel kanker yang didapat pada penyinaran sudut $0^{\circ}$ sangat kecil.

Tabel 2.. Dosis serap untuk target penyinaran PTV (bawah pusat sel kanker)

\begin{tabular}{lrrr}
\hline \multirow{2}{*}{ Organ } & \multicolumn{3}{c}{ latero-lateral } \\
\cline { 2 - 4 }$(\max 1 \mathrm{~Gy})$ & $\begin{array}{c}270^{\circ} \\
(\max 1 \mathrm{~Gy})\end{array}$ & $\begin{array}{c}\text { Gab (max } \\
2 \mathrm{~Gy})\end{array}$ \\
\hline Kanker NF & 1,446 & 1,446 & 2,898 \\
Mata kanan & 0,184 & 0,183 & 0,371 \\
Mata kiri & 0,270 & 0,269 & 0,543 \\
Lidah & 0,064 & 0,064 & 0,130 \\
Tiroid & 0,079 & 0,079 & 0,274 \\
Getah Ben & 0,006 & 0,006 & 0,596 \\
\hline
\end{tabular}

Hasil simulai yang diperoleh dari teknik penyinaran supraclave dan lateral menunjukkan organ-organ yang berada pada posisi yang lebih dalam dan lebih jauh dari sel kanker dan kelenjar getah bening sebagai target radiasi akan menyerap dosis yang lebih rendah. Jika dibandingkan antara hasil simulasi penyinaran supraclave dan latero-lateral untuk target GTV dan PTV terdapat perbedaan terimaan dosis pada setiap organ. Dibanding kanker nasofaring dan lidah, kelenjar tiroid menyerap dosis lebih tinggi untuk penyinaran supraclave (sudut $0^{\circ}$ ) dibandingkan dengan teknik lateral (sudut $90^{\circ}$ dan $270^{\circ}$ ) target radiasi GTV maupun PTV. Hal tersebut karena penyinaran supraclave, target radiasi adalah daerah kelenjar getah bening. Sedangkan sel kanker, mata, dan esofagus menyerap dosis lebih tinggi saat dilakukan penyinaran lateral (sudut $90^{\circ}$ dan $270^{\circ}$ ) target pusat sel kanker. Hal itu disebabkan organorgan tersebut adalah target radiasi sehingga terkena lebih banyak radiasi dibandingakan organ-organ lainnya. Organ esofagus, trakea dan tulang belakang menyerap dosis lebih tinggi pada penyinaran lateral (sudut $90^{\circ}$ dan sudut $270^{\circ}$ ) target radiasi bawah sel kanker.

Secara umum dosis total yang diberikan pada sel kanker nasofaring adalah sebesar 70 Gy[3,4]. Dosis total radiasi dibagi menjadi dosis yang lebih kecil disebut fraksi. Dosis serap radiasi yang direncanakan pada target sel kanker setiap fraksi penyinaran adalah 4 Gy dalam satu 
kali penyinaran yang terdiri dari 2 Gy untuk penyinaran lateral (sudut $90^{\circ}$ dan $270^{\circ}$ ) dan 2 Gy untuk penyinaran supraclave. Sedangkan organ normal sekitar sel kanker tidak boleh menerima dosis melebihi batas ambang, yaitu 1,6 Gy [13].

Berdasarkan hasil simulasi dosis serap total yang didapatkan nilai dosis serap pada sel kanker target penyinaran GTV maupun PTV melebihi batas penyinaran per fraksi yaitu $2 \mathrm{~Gy}$. Sedangkan penyinaran supraclave dosis serap yang didapat kurang memenuhi dosis yang ditetapkan yaitu 2 Gy. Hal tersebut disebabkan oleh faktor geometri phantom yang tidak rata, sel kanker terletak lebih dekat permukaan, sehingga saat penyinaran radiasi datang tegak lurus tepat mengenai sel kanker yang menyebabkan perbedaan terimaan dosis serap. Selain itu faktor densitas, volume dan massa yang terdapat pada masing-masing organ mempengaruhi setiap jumlah dosis serap, semakin besar massa organ maka semakin kecil jumlah dosis serap, begitu sebaliknya semakin kecil massa organ maka semakin banyak dosis yang diserap [14].

\section{Distribusi Dosis Serap Total (kurva idososis) target GTV dan PTV}

Distribusi dosis serap total pada Phantom organ kepala sampai dada dibuat dalam bentuk kontur untuk mengetahui sebaran dosis yang diterima terhadap kedalaman. Kontur ini dapat menunjukkan distribusi dosis serap dalam satu sayatan Phantom (koordinat xz), yaitu pada titik pusat sel kanker menuju kedalaman (sumbu z) dan menuju sisi kanan dan kiri Phantom (sumbu $\mathrm{x})$ agar dapat melihat sebaran dosis radiasi terhadap organ-organ yang berada disekitar sel kanker. Distribusi dosis serap ini diperoleh dari hasil running program MCNPX menggunakan tally $f 5$ yang menghasilkan nilai fluks energi dengan satuan $\mathrm{MeV} / \mathrm{cm} 2$, kemudian dikonversi ke satuan dosis serap. Distribusi dosis serap total untuk target GTV disajikan pada Gambar 3.

Luas lapangan pada penyinaran supraclave berukuran $(17 \times 9) \mathrm{cm}^{2}$. Penyinaran supraclave (sudut $0^{\circ}$ ) target yang diradiasi adalah kelenjar getah bening (bagian dada), sehingga sebaran dosis serap yang paling besar diterima adalah bagian dada bukan bagian pusat sel kanker (daerah kepala).

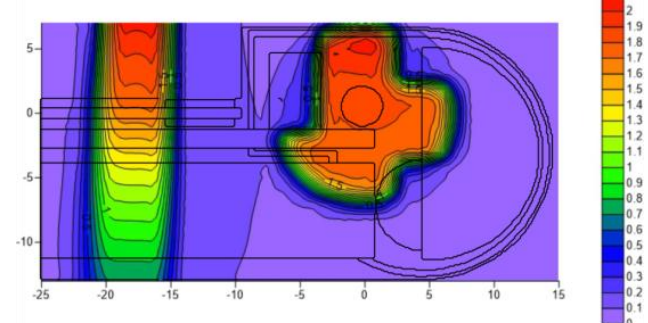

Gambar 3. Kurva isodosis gabungan tiga penyinaran (sudut $0^{\circ}, 90^{\circ}$ dan $270^{\circ}$ ) untuk target GTV untuk sayatan koordinat-xz.

Kurva isodosis (Gambar 3) terlihat merata ke organ sekitar sel kanker, karena pemberian lapangan radiasi yang luas sehingga radiasi sumber mempunyai jangkaun luas juga pada organ sekitar [14]. Hasil kontur penyinaran lateral dengan target radiasi daerah pusat sel kanker (GTV) menunjukan bahwa yang paling tinggi terkena radiasi adalah permukaan pada daerah hidung, akibatnya penyinaran dengan target radiasi pusat sel kanker jika terus menerus dilakukan akan menimbulkan efek berbahaya. Sehingga dilakukannya penyinaran laterolateral dengan target penyinaran yang berada pada daerah bawah sel kanker, PTV (Gambar 4) dengan merujuk pada penyinaran teknis di RSUD Margono

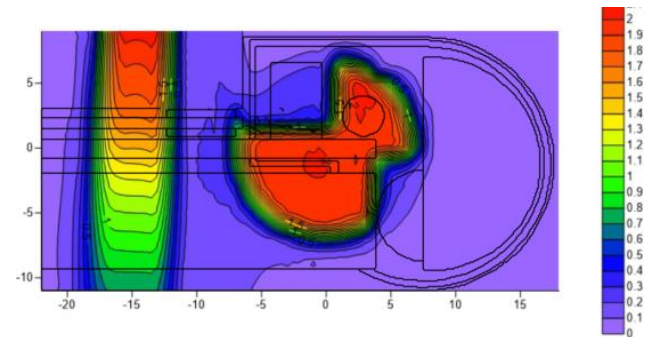

Gambar 4. Kurva isodosis gabungan tiga penyinaran (sudut $0^{\circ}, 90^{\circ}$ dan $270^{\circ}$ ) untuk target PTV untuk sayatan koordinat-xz.

\section{KESIMPULAN}

Total Dosis serap (gabungan) target radiasi GTV untuk kanker nasofaring terekam sebesar 2,99 Gy dan organ lidah 0,162 Gy, sedangkan pada target radiasi PTV, kanker nasofaring menerima 2,89 Gy, dan organ lidah 0,130 Gy.

\section{UCAPAN TERIMA KASIH}

Disampaikan kepada Lembaga Penelitian dan Pengabdian kepada Masyarakat LPPM UNSOED atas dana penelitian dan Unit Radioterapi RSUD Prof. Margono Soekarjo atas 
akses data dan rujukan fasilitas dan kerjasamanya dalam penelitan ini.

\section{PUSTAKA}

[1] Hasan, Isnaniah dan Irwan Ramli, "Brakhiterapi Nasofaring. Radioterapi \& Onkologi Indonesia. 5(2) (2014) 77 - 84

[2] Asroel, A Harry, Penatalaksa-naan Radioterapi pada Karsinoma Nasofaring. Fakultas Kedokteran. Universitas Sumatera Utara, 2002.

[3] KPKN, Komite Penanggulangan Kanker Nasional. Pedoman Nasional Pelayanan Kedokteran Kanker Nasofaring. Kementerian Kesehatan Republik Indonesia, 2017.

[4] Barrett, Ann., Dobbs, Jane., Morris, Stephen, dan Roques, Tom., Practical Radiotherapy Planning. Fourth Edition. Hachette UK Company 338 Euston Road, London NW1 3B"H, 2009.

[5] Çeçen, Yiğit., Monte Carlo radiation transport in external beam radiotherapy". Bitlis Eren Univ J Sci \& Technol., 3 (2013) 1-5

[6] Immanuel, Richard B., "Evaluasi Verifikasi Lapangan Radiasi Pada Kasus Kanker Serviks Dan Kanker Nasofaring Menggunakan Pesawat Terapi Co-60". Skripsi. Fakultas Matematika Dan Ilmu Pengetahuan Alam Program Studi S1 Fisika Peminatan Fisika Medis Dan Biofisika Depok, 2010.
[7] Khan, F. M., The Physics of Radiation Therapy. Edisi Kelima. William and Wilkins. Maryland. USA, 2014.

[8] Pelowitz, Denise. B., MCNPX User Manual Versi 2.6.0. LA-CP-07-1473. Los Alamos National Laboratory. New Mexico, 2008.

[9] X-5 Monte Carlo Team, MCNP - "A General Monte Carlo N-Particle Transport Code Version 5". LA-UR-03-1987. Los Alamos National Laboratory. New Mexico, 2003.

[10] Chang, Shu-Jun., Shih-Yen Hung, Yan-Lin Liu, Shiang-Huei Jiang, Construction of Taiwanese Adult Reference Phantoms for Internal Dose Evaluation. PLoS ONE, 11(9) (2016) 1 - 14

[11] Santoso, Boedy Setya., Bakti Surarso, Widodo Ario Kentjono, Radioterapi Pada Karsinoma Nasofaring, Jurnal THT-KL, 2(3) (2009) 134 - 141

[12] Lazarine, Alexis D., Medical Physics Calculations With MCNPTM: A Primer. Thesis. Texas A\&M University,2006

[13] Berris, T., Mazonakis, M., Stratakis, J., Tzedakis, A., Fasoulaki, A., Damilakis, J., "Calculation of Organ Doses From Breast Cancer Radiotherapy: A Monte Carlo Study", Journal Of Applied Clinical Medical Physics, 14(1) (2013) 133-146.

[14] Nugraheni, D.T., Gunawan, V., Anam, C., "Prediction of 2D Isodose Curve on Arbitrary Field Size in Radiation Treatment Planning System (RTPS)", Jurnal Sains dan Matematika, 23(1) (2015) 7-13 